\title{
ADULT COLO-COLONIC INTUSSUSCEPTIONS WITH LIPOMA AS THE LEADING POINT- A CASE REPORT
}

Samir Ranjan Nayak², Dilip Kumar Soren², Ganni Bhaskara Rao33, Ganta Kiran4, J Kodanda Ram5.

\section{HOW TO CITE THIS ARTICLE:}

Samir Ranjan Nayak, Dilip Kumar Soren, Ganni Bhaskara Rao, Ganta Kiran, J Kodanda Ram. "Adult colo-colonic intussusceptions with lipoma as the leading point- a case report". Journal of Evolution of Medical and Dental Sciences 2013; Vol2, Issue 28, July 15; Page: 5163-5166.

ABSTRACT: Adult Colo-colonic intussusception is a rare presentation. Colo-colonic intussusceptions presenting as history of diarrhea and occasionally pain abdomen and undiagnosed for 2 months is unusual. We report a case of Colo-colonic intussusceptions diagnosed by USG abdomen and then colonoscopy and further confirmed by laparotomy the cause being a sub mucosal lipoma.

KEY WORDS: Colo-colonic intussusception, lipoma

INTRODUCTION: Intussusception occurs when a portion of intestine is telescoped into adjacent intestinal segments. Intussusception in adults is rare. Colo-colonic intussusception in the adult is almost always a complication of pre-existing colonic disease, usually neoplasm or post operative condition.[1] however neoplasm is the most common cause and found $65 \%$ of cases. Malignant tumors are common than benign neoplasm. Lipoma is frequently the precipitating causes in the benign tumor group [2]

CASE REPORT: A 40-year male presented with history of repeated pain abdomen and loose motion since 2 month and was on treatment with antibiotics and antispasmodics at various hospitals on OPD basis. On admission patient was afebrile. The abdomen was soft .There was mild tenderness over left iliac fossa region with positive bowel sounds, Digital rectal examination reveled no abnormality. The blood counts were within normal limits. Plain X ray abdomen showed no fluid levels. Abdominal sonogram showed layered mass at left iliac fossa with pseudo-kidney appearance- ? Colonic intussusceptions seen (figure 1). Colonoscopy done suggested friable mass projecting to sigmoid colon (figure 2). Laparotomy done and the findings were intussusceptions of descending colon due to a polypoid mass in colon with edematous proximal colon and mesocolon .(figure 3 and 4).Resection and end to end anastomosis was done. Postop recovery was satisfactory. Histopathology examination was ulcerated lipomatous polyp with no evidence of malignancy

DISCUSSION: Intussusception occurs when a segment of bowel (intussusceptum) telescopes into the segment adjacent to it (intussuscipiens). The condition occurs more frequently in children, where enlarged Payer's patches are the most common lead-point for the intussusception.

Intussusception in adults is rare, accounting for $5 \%$ of all intussusceptions. The intussusception is associated with a pathological lead-point in $90 \%$ of cases. [3, 4]

Review literature revels majority (58\%) of intussusceptions in the large bowel had a malignant lead point [3,]. Most often, this was adenocarcinoma, but, lymphoma and leiomyosarcoma were also reported. Benign colonic lead points included lipoma, adenomatous polyps, GIST endometriosis, and previous surgical anastomoses. 
Colo-colonic intussusception caused by a lipoma, as in the present case, is rare in the general population and the majorities are asymptomatic. Next to adenomatous polyp this mesenchymal tumors are the most common benign tumors of colon. [ 5 ] They occur more commonly in the caecum and ascending colon, although left-sided lesions may cause intussusception more frequently. Intussusception without a lead point is transient but an Intussusception with lead point is persistent or recurrent [5]

Adult intussusception usually has a chronic or sub-acute presentation and is often difficult to diagnose because of vague symptoms. An abdominal mass is palpable in $24-42 \%$ of patients.

Abdominal USG may also useful in the diagnosis particularly in the hands of skilled operator, The hyper echoic well circumscribed layered mass in the colon with diminished blood flow in Doppler scan is highly suggestive of colonic intussusception with lipoma may be the lead point [6]

CT is the most accurate imaging modality in diagnosis with the pathognomonic appearance of a 'target' lesion. [5, 7 ] Magnetic resonance imaging (MRI), barium studies, can also demonstrate intussusception.

Surgery is the standard treatment for colonic lipoma greater than $2 \mathrm{~cm}$ in size [8] .The treatment includes limited or segmental resection, hemicolectomy, or subtotal colectomy. The modalities of intervention usually depends on the lipoma size, location, and the presence or absence of disease complications [8]. In the presented case limited resection and end to end, anastomosis was carried out. Both intraoperative reduction and resection without reduction has been advocated. The advantages of intraoperative reduction are that if a benign cause is identified then an unnecessary major resection can be avoided. (9)

\section{AUTHOR INFORMATION:}

$\mathrm{S} \mathrm{R} \mathrm{N}--$ performed the surgery and was involved in drafting the manuscript revising the intellectual content

GK, JKR, DKS participated in surgery was involved in drafting the manuscript

GBR participated in surgery

\section{REFERENCES:}

1. Haas EM, Etter EL, Ellis S, Taylor VT.Adult intussusception. Am J Surg 2003; 186:75- 6.

2. Paresh Desai, MD; MayaBhat, MD; Asutosh desai, DMRD; Susila pal, DMRD. Colocolic Intussusception with lipoma as the leading point. Applied Radiology 2009; 38(9).

3. Rogers SO, Maggie CL, Ashley SW. Giant colonic lipoma as a lead point for colo-colonic Intussusception. Surgery 2002; 131:687-8.

4. Aftab S Shaikh, Waquar Ahmed Ansari, et al .colonic Intussusception in an adult due to pedunculated lipoma. Bombay Hospital Journal 2009; 51(4):536-539.

5. Alkim C,Sasmaz N, Alkim H, Caglikulekci M, Turhan $n$. Sonographic findings in intussusception caused by lipoma in the muscular layer of colon. J clin ultrasound 2001; 5: 298-301.

6. Eric Chun-Hung Lai, JJanel Fung-Yee Lee, Simon SIu -Man Ng, Raymond Ying_chang Yiu, Ka Lau Leung . Adult colonic Intussusception 2005;9(3):64-67

7. Huang BY, Warshauer DM. Adult intussusception: diagnosis and clinical relevance. Radiol Clin N Am 2003; 41:1137-51. 


\section{CASE REPORT}

8. L. Jiang, L. S. Jiang, F. Y. Li et al., "Giant submucosal lipoma located in the descending colon: a case report and review of the literature," World Journal of Gastroenterology, 2007;13(42)5664- 5667.

9. Nicholas Howard, Nagaragen Pranesh, Paul Carter colo colonic intussusception secondary to lipoma. International journal of surgery case report 2012 ; 3(2): 52-54

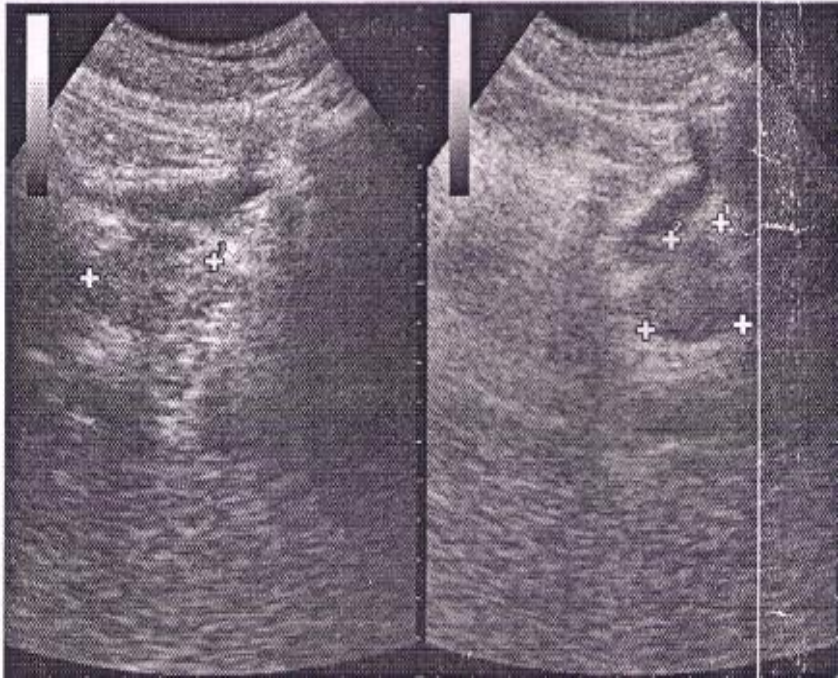

Fig.1 USG abdomen-left colon shoeing layered bowel mass

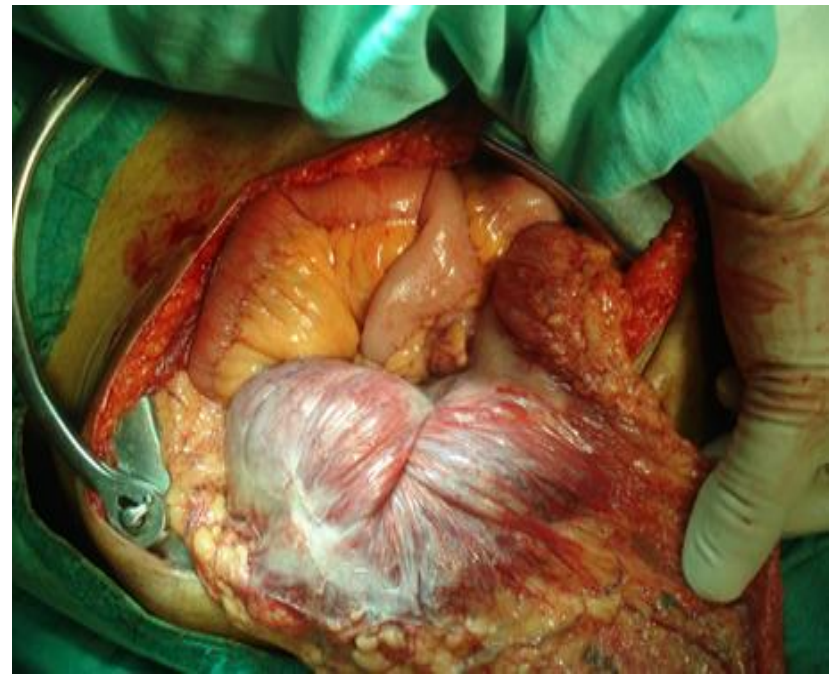

Fig.3 laparotomy- edematous colon and mesocolon

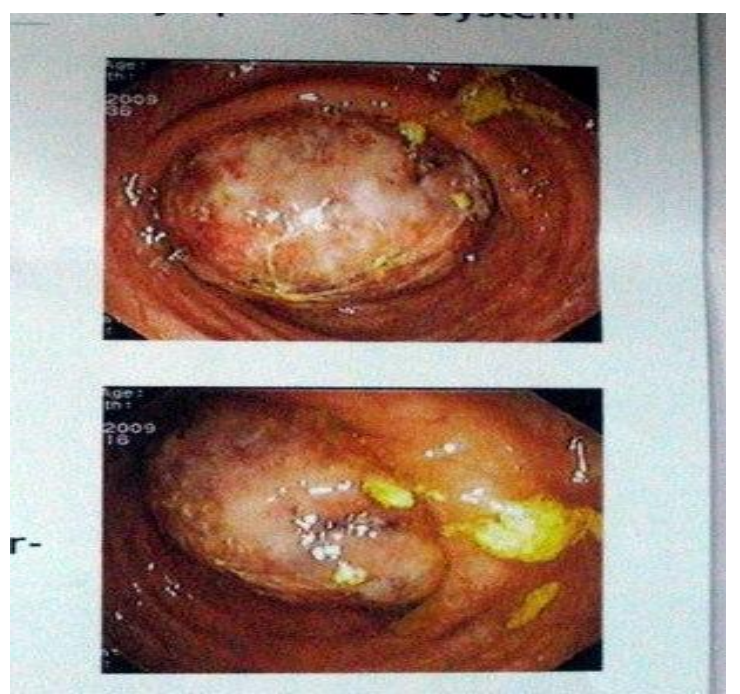

Fig. 2 colonoscopy-mass protruding to descending colon

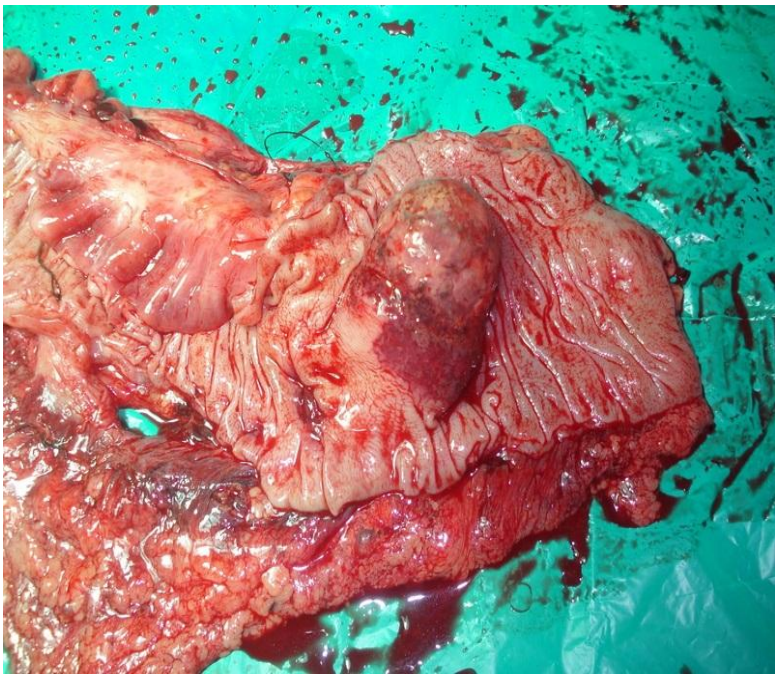

Fig.4 colonic lipoma causing intussusceptions 


\section{CASE REPORT}

\section{AUTHORS:}

1. Samir Ranjan Nayak

2. Dilip Kumar Soren

3. Ganni Bhaskara Rao

4. Ganta Kiran

5. J Kodanda Ram

\section{PARTICULARS OF CONTRIBUTORS:}

1. Associate Professor, Department of Surgery, GSL Medical College And General Hospital.

2. Assistant Professor, Department Of Surgery, GSL Medical College And General Hospital.

3. Professor, Department Of Surgery, GSL Medical College And General Hospital.

4. Postgraduate, Department of Surgery, GSL Medical College And General Hospital.
5. Postgraduate, Department Of Surgery, GSL Medical College And General Hospital

NAME ADRRESS EMAIL ID OF THE CORRESPONDING AUTHOR:

Dr. Samir Ranjan Nayak, GSL medical College, Rajahmundry, 533105

East Godavari Dist. AP

E-mail: drsamirnayak@gmail.com

Date of Submission: 27/06/2013.

Date of Peer Review: 28/06/2013.

Date of Acceptance: 03/07/2013.

Date of Publishing: 12/07/2013 